\title{
Pulverização pneumática eletrostática com tratamentos fúngicos alternativos no manejo de videira comum em Laranjeiras do Sul/PR
}

\section{Tiago José Reis Stawniczyi \\ Claudia Simone Madruga Lima}

Curso de Agronomia. Universidade Federal da Fronteira Sul, UFFS Campus Laranjeiras do Sul, PR, Brasil.

E-mails: tiago.jrs@hotmail.com claudia.lima@uffs.edu.br

Recebido em: 13 abril 2018. Aceito em: 12 maio 2018.

DOI: http://dx.doi.org/10.21674/2448-0479.43.470-477

\section{Resumo}

A viticultura é tradicional em diversas regiões brasileiras, mas existem fatores que podem ser limitantes em sua produtividade, como por exemplo, os fungos patogênicos. Para controle é utilizado fungicidas no sistema convencional, que podem causar danos à saúde humana e meio ambiente. Como método alternativo pode-se utilizar extratos ou caldas naturais, tendo como exemplo, o extrato de cinamomo e a calda bordalesa. O sistema de pulverização eletrostática é outra alternativa, pois com emprego desta tecnologia nas aplicações de produtos se aumenta a eficiência da aplicação dos tratamentos nas plantas. Dessa forma, objetivou-se com este trabalho verificar a eficiência da pulverização eletrostática com tratamentos fúngicos alternativos na videira comum em Laranjeiras do Sul/PR. Foram realizadas pulverizações de calda a base de extrato aquoso de cinamomo e calda bordalesa em plantas de 'Niágara Branca', 'Niágara Rosada' e 'Bordô', as pulverizações foram com presença e ausência de carga. As variáveis avaliadas foram: a deposição nas plantas das caldas (\%) aplicadas através de escala própria e volume de calda $(\mathrm{mL})$ utilizado para cada tratamento nas diferentes cultivares. Para as cultivares Niágara Branca e Niágara Rosada, a calda comercial de Cuprofix ${ }^{\circledR}$ apresentou maior volume de calda gasto para realizar a aplicação em relação a testemunha, ambas não diferiram do extrato de cinamomo. Quanto ao fator presença e ausência de carga, a cultivar Niágara Branca com o sistema de indução ligado resultou em menor volume de calda utilizado. A pulverização eletrostática promoveu menor volume de calda para aplicação de produto, e os diferentes tratamentos fungicidas influenciam no volume de calda aplicado nas plantas.

Palavras-chave: Indução. Carga. Melia azedarach L. Calda. Bordalesa. 


\section{Abstract \\ Electrostatic pneumatic spraying with alternative fungal treatments in common grape management in Laranjeiras do Sul / PR}

Viticulture is traditional in several Brazilian regions, but there are factors that may be limiting in its productivity, such as pathogenic fungi. For control is used fungicides in the conventional system, which can cause harm to human health and environment. As an alternative method, natural extracts or syrups may be used, for example cinnamon extract and Bordeaux syrup. The electrostatic spraying system is another alternative, since using this technology in the applications of products increases the efficiency of the application of the treatments in the plants. In this way the objective of this study was to verify the efficiency of electrostatic spraying with alternative fungal treatments on the common grapevine in Laranjeiras do Sul / PR. Spray sprays based on aqueous extract of cinnamon and Bordeaux syrup in 'Niagara Branca', 'Niagara Rosada' and 'Bordô' plants were sprayed, spraying with presence and absence of charge. The evaluated variables were: the deposition in the plants of the groves (\%) applied through their own scale and volume of syrup $(\mathrm{mL})$ used for each treatment in the different cultivars. For the cultivars Niagara Branca and Niagara Rosada, the commercial syrup of Cuprofix® presented higher volume of syrup used to carry out the application in relation to the control, both did not differ from the cinnamon extract. As for the factor presence and absence of load, the cv. Niagara Branca with the connected induction system resulted in a smaller volume of syrup used. The electrostatic spray promoted a lower volume of syrup for product application, and the different fungicide treatments influenced the volume of syrup applied in the plants.

Keywords: Induction. Charge. Melia azedarach L. Syrup. Bordalesa.

\section{Introdução}

Atividade tradicional em diferentes regiões brasileiras, a viticultura, tem vinhedos estabelecidos em regiões desde o extremo Sul do país, até regiões próximas ao Equador (VIEIRA; WATANABE; $B R U C H, 2012)$. A uva é uma fruta economicamente importante no mundo, com uma área de aproximadamente 81 mil hectares utilizada para a vitivinicultura no Brasil. Nas últimas décadas, ocorreu desenvolvimento na ciência e tecnologia que auxiliou o aumento da produção e produtividade desta cultura (FARIA et al., 2016).

Existem fatores que podem ser limitantes para a produtividade da videira, que tende ao desenvolvimento de patógenos em seu período vegetativo e reprodutivo quando ocorrem condições edafoclimáticas favoráveis ao desenvolvimento de doenças. Estas podem se desenvolver em diferentes partes da planta, como nas raízes, troncos, ramos, folhas, brotos e cachos. Algumas doenças podem provocar grandes perdas caso não se adotem medidas de controle adequadas, como por exemplo, 
míldio (Plasmopara vitícola B.), oídio (Uncinulanecator S.), antracnose (Elsinoeampelina S.) e ferrugem (Phakopsoraeuvitis O.) (NAVES et al., 2005).

O uso de fungicidas é empregado no sistema convencional de cultivo, sendo utilizado como modo de assegurar a produção, mas pode causar efeitos colaterais para a saúde humana, animal e o ambiente. Um grave problema na utilização dos agrotóxicos é o uso indiscriminado do produto, que pode resultar em contaminação do solo, água, animais, selecionar patógenos resistentes, ocasionando desequilíbrio biológico, assim, mostra-se a necessidade de adaptarmos métodos alternativos em culturas tradicionais como a videira (SILVA, 2014).

Entre os métodos alternativos que vem sendo utilizados pelos agricultores no controle de doenças, está uso de extratos ou caldas naturais, como por exemplo, o cinamomo (Meliaazedarach L.). Essa espécie pertence à família Meliaceae, que apresentam um grande grupo de substâncias bioativas, as quais possuem características de efeito biológico, como a azadiractina, meliantrol e salanina. Essas substâncias produzem efeitos diferentes e nocivos sobre uma ampla quantidade de fitopatógenos (RODRIGUES et al., 2010).

Outro produto comumente utilizado na agricultura como alternativa é a calda bordalesa, este fungicida é considerado um dos produtos eficientes no combate de algumas doenças de plantas, principalmente das frutíferas (ANDREAZZA et al., 2013). A calda bordalesa é um dos produtos de maior aplicação na viticultura nacional, possui vantagens como baixo custo e baixa toxidez ao homem e animais. Mas deve-se ter atenção nas concentrações de cobre na planta, essas se elevadas podem ser muito tóxicas, resultando em sintomas como clorose, necrose, descoloração da folha e inibição de crescimento da raiz (PERUCH et al., 2007).

A pulverização eletrostática consiste basicamente em um sistema em que as gotas são eletrificadas com cargas positivas ou negativas, assim, fazendo com que a gota não mude sua trajetória entre o pulverizador e o alvo através da atração por este, devido a busca por neutralidade da mesma, obtendo uma aplicação direcionada, reduzindo perdas para o ambiente e redução de volume de calda (SASAKI et al., 2015). Portanto, o sistema de pulverização eletrostática é uma alternativa ao método de pulverização tradicional, pois com emprego desta tecnologia nas aplicações de produtos aumentase a eficiência da aplicação dos tratamentos nas plantas.

O objetivo neste trabalho foi analisar a eficiência da pulverização pneumática eletrostática com tratamentos fúngicos alternativos no manejo de videira comum em Laranjeiras do Sul/PR.

\section{Material e Métodos}

O trabalho foi realizado em propriedade particular localizada em Laranjeiras do Sul - PR $\left(25^{\circ} 24^{\prime} 12.5^{\prime \prime} \mathrm{S}, 5^{\circ} 23^{\prime} 46.7^{\prime \prime W}\right)$. Foram utilizadas videiras das cultivares Niágara Branca, Niágara Rosada e Bordô, com aproximadamente sete anos de idade. Conduzidas em sistema latada, com altura de aproximadamente 1,80 m, espaçamento de 1,2 m entre plantas e 2,0 m entre linhas.

As plantas foram submetidas a pulverizações pneumáticas eletrostáticas com diferentes produtos, sendo os tratamentos os seguintes: presença ou ausência de carga na aplicação, associados 
a três caldas/produtos aplicados de forma independente. As caldas aplicadas foram: calda comercial bordalesa (Cuprofix ${ }^{\circledR}$ ); calda natural - produto a base de extrato aquoso de cinamomo: $50 \mathrm{~mL} \mathrm{~L}^{-1}$ de extrato, obtido de acordo com o descrito em trabalho por Silva (2011), acrescentado 2,5 $\mathrm{mL} \mathrm{L}^{-1}$ de óleo mineral como adjuvante e a testemunha (água).

As pulverizações foram realizadas após a poda em setembro de 2016, com uso de equipamentos de proteção individual. A pulverização pneumática eletrostática foi realizada de modo a atingir ponto de escorrimento nas plantas, utilizando como equipamento de pulverização um compressor de ar direto Jet Master Schulz ${ }^{\circledR}$, uma pistola de ar direto com capacidade de $700 \mathrm{~mL}$, um conversor de alta tensão ligado à um anel de cobre na extremidade do bico da pistola, o anel contendo $3,0 \mathrm{~cm}$ de diâmetro e $3,0 \mathrm{~cm}$ de comprimento.

As avaliações realizadas a campo foram: deposição dos tratamentos, com papéis (amarelos) tipo mata-borrão com 1,5 cm de largura e 3,0 cm de comprimento, os quais foram colocados dois na região adaxial e dois na região abaxial das folhas de forma aleatória, sendo adicionada a calda de pulverização o corante artificial azul Arcolor ${ }^{\circledR}$.A avaliação de gotas foi realizada visualmente por meio de escala própria (Figura 1), onde as amostras apresentam valores percentuais em relação a área do papel pulverizada sendo: $0 \%$ de área pulverizada (não atingida pela pulverização), 20\%, 40\%, 60\%, $80 \%$ e $100 \%$ de área pulverizada (completamente atingida pela pulverização). Para o volume de calda, foi mensurada a quantidade do preparado a ser aplicado e a quantidade remanescente após a aplicação, para isso utilizando recipiente graduado de $500 \mathrm{~mL}$.

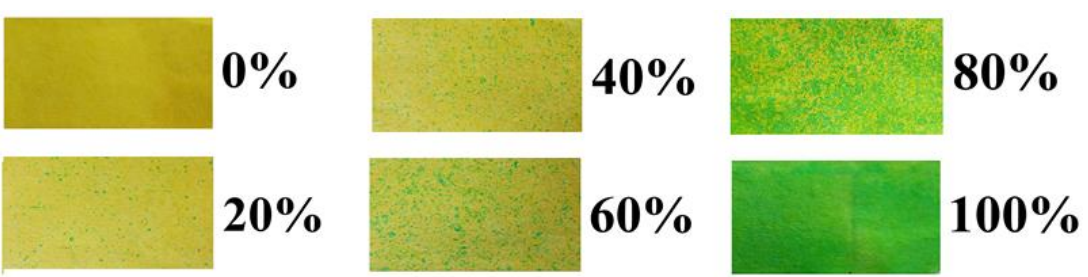

Figura 1 - Escala em níveis aproximados em porcentagem (\%) de deposição de calda que representa: 0\% de área pulverizada, $20 \%$ de área pulverizada, $40 \%$ de área pulverizada, $60 \%$ de área pulverizada, $80 \%$ de área pulverizada e $100 \%$ de área pulverizada.

O delineamento experimental para cada uma das três cultivares foi constituído em esquema bifatorial (3x2), caldas (produtos) $x$ cargas (presença ou ausência de carga). Para cada cultivar foram utilizadas três repetições por tratamento, cada uma representada por três plantas. Foi realizado a análise de variância (ANOVA) e teste de Tukey com nível significância de 5\% com auxílio do software estatístico Assistat. 


\section{Resultados e Discussão}

Para todas as variáveis analisadas não houve interação entre os fatores. Para a variável volume de calda os fatores atuaram de forma isolada (Tabela 1). A cultivar bordô não diferiu significativamente para volume de calda, sendo os maiores valores obtidos com a calda de extrato de cinamomo. Para as cultivares Niágara Branca e para Niágara Rosada, a calda comercial de Cuprofix ${ }^{\circledR}$ apresentou maior volume de calda gasto para realizar a aplicação.

Tabela 1 - Volume de calda/produto (mL planta-1) aplicadas no cultivo de 'Niágara Branca', 'Niágara Rosada' e 'Bordô' em função dos diferentes tipos de caldas aplicadas.

\begin{tabular}{cccc}
\hline \multirow{2}{*}{ Caldas } & \multicolumn{3}{c}{ Cultivares } \\
\cline { 2 - 4 } & $\begin{array}{c}\text { Niágara Branca } \\
\left(\mathrm{mL} \mathrm{planta}^{-1}\right)\end{array}$ & $\begin{array}{c}\text { Niágara Rosada } \\
\left(\mathrm{mL} \mathrm{planta}^{-1}\right)\end{array}$ & $\begin{array}{c}\text { Bordô } \\
\left(\mathrm{mL} \mathrm{planta}^{-1}\right)\end{array}$ \\
\hline Cuprofix & $389,94 \mathrm{a}$ & $399,44 \mathrm{a}$ & $384,16 \mathrm{a}$ \\
Extrato de Cinamomo & $312,66 \mathrm{ab}$ & $350,83 \mathrm{ab}$ & $416,66 \mathrm{a}$ \\
Testemunha & $308,44 \mathrm{~b}$ & $291,11 \mathrm{~b}$ & $386,66 \mathrm{a}$
\end{tabular}

*As médias seguidas pela mesma letra na coluna não diferem estatisticamente entre si. Teste de Tukey $(p>0,05)$.

Os resultados encontrados para volume de calda podem estar relacionados com a afirmação de Souza et al. (2012), que consideram possível que ocorra variação entre as cultivares associada aos diferentes padrões de cera sobre a epiderme, determinando diferentes graus de molhabilidade da superfície das folhas. E ainda, que a composição das caldas pode influenciar no volume de calda para o molhamento foliar adequado, pois a camada cerosa da folha pode determinar o volume em função do nível de afinidade particular de cada calda com a camada superficial da folha.

De acordo com o conteúdo da calda, pode ocorrer variação na capacidade de carregar as gotas, pois segundo Cunha e Carvalho (2005), a calda pode variar quanto a espessura, aumentando o tamanho das gotas, que em excesso, pode dificultar a cobertura do alvo e provocar escorrimento. Também deve-se considerar que quanto maiores as gotas produzidas, maior é a dificuldade para as mesmas obterem cargas do sistema de indução.

Conforme Chaim e Wadt (2015), no processo de indução com eletrificação indireta as gotas carregam-se na presença de um intenso campo eletrostático, com a produção de gotas pequenas, forças elétricas podem ser induzidas em grandeza adequada para controle de seu movimento, pois exigem um campo eletrostático com menor intensidade para sua eletrificação. Assim, a possível variação do tamanho das gotas pela composição da calda pode ter influenciado na eficiência da pulverização eletrostática e demandando maior volume para a aplicação do produto.

Em trabalho com as propriedades físicas das caldas, Sasaki et al., (2015), também verificou que na eletrificação das gotas, houve aumento de até $50,14 \%$ na relação carga/massa com o uso de adjuvantes, demonstrando que auxiliam na pulverização eletrostática, onde os adjuvantes que reduziram o diâmetro das gotas pulverizadas, melhoraram a capacidade de eletrificação das mesmas. 
Quanto ao fator presença e ausência de carga para variável resposta volume de calda, somente para cultivar Niágara Branca houve diferença significativa (Tabela 2). Para a cultivar Niágara Branca a aplicação realizada com o sistema de carga presente resultou em menor volume de calda utilizado. Para as cultivares Niágara Rosada e Bordô, não houve significância $(p>0,05)$ entre a presença ou ausência de carga utilizada na aplicação.

Tabela 2 - Volume de calda (mL planta-1) aplicadas no cultivo de 'Niágara Branca', 'Niágara Rosada' e 'Bordô' em função da presença e ausência de carga na pulverização eletrostática.

\begin{tabular}{cccc}
\hline Carga & $\begin{array}{c}\text { Niágara Branca } \\
\left(\mathrm{mL} \mathrm{planta}^{-1}\right)\end{array}$ & $\begin{array}{c}\text { Niágara Rosada } \\
\left(\mathrm{mL} \mathrm{planta}^{-1}\right)\end{array}$ & $\begin{array}{c}\text { Bordô } \\
\left(\mathrm{mL} \mathrm{planta}^{-1}\right)\end{array}$ \\
\hline Presente & $311,92 \mathrm{~b}$ & $339,26 \mathrm{a}$ & $396,66 \mathrm{a}$ \\
Ausente & $366,11 \mathrm{a}$ & $350,00 \mathrm{a}$ & $395,00 \mathrm{a}$
\end{tabular}

*As médias seguidas pela mesma letra na coluna não diferem estatisticamente entre si pelo Teste de Tukey $(p>0,05)$.

Esse menor volume de calda obtido nos tratamentos com presença de carga, provavelmente está atrelado com uma melhor aplicação do produto no alvo, pelo uso de cargas geradas pelo sistema de pulverização eletrostática empregado, causando um maior direcionamento da calda com a planta e reduzindo perdas do produto aplicado. Serra et al. (2008), observaram a atuação do fator de eletrificação e tamanho de gotas, em trabalho sobre pontas de pulverização e eletrificação das gotas na deposição da calda em plantas de crisântemo (Chrysanthemum morifolium R.), em que pontas com gotas de menor diâmetro apresentaram maiores depósitos na superfície abaxial da folha ao utilizar-se pulverização eletrostática, não ocorrendo com pulverização de gotas com maior diâmetro e desprovidas de carga elétrica.

Em estudo sobre deposição e uniformidade de distribuição da calda de aplicação em plantas de café (Coffea sp. L.), utilizando a pulverização eletrostática, Sasaki et al. (2013), de mesmo modo obtiveram resultados positivos com a pulverização, onde o sistema eletrostático proporcionou aumento de 37\% na deposição de calda da aplicação em relação ao sistema eletrostático desligado.

Para a deposição dos tratamentos nas cultivares Niágara Branca, Niágara Rosada e Bordô, todas apresentaram uma média superior de deposição, porém não houve significância no teste (Tabela 3). Em trabalho de Magno Júnior et al. (2011), no desenvolvimento de um dispositivo eletrônico para atração de gotas da aplicação eletrostática em plantas cítricas, ocorreu um resultado semelhante, onde nas condições com carga elétrica na gota apresentaram médias superiores das deposições sem carga elétrica, mas também sem diferença significativa. Resultado que também pode ter sido afetado pela força do vento, caso maior do que a força elétrica induzida na gota. 
Tabela 3 - Deposição de calda (\%) aplicada no cultivo de 'Niágara Branca', 'Niágara Rosada' e 'Bordô' em função da presença e ausência de carga na pulverização eletrostática.

Carga Niágara Branca (\%) Niágara Rosada (\%) Bordô (\%)

\begin{tabular}{lccc}
\hline Presente & $71,11 a$ & $71,11 \mathrm{a}$ & $64,44 \mathrm{a}$ \\
Ausente & $55,55 \mathrm{a}$ & $64,44 \mathrm{a}$ & $57,77 \mathrm{a}$
\end{tabular}

*As médias seguidas pela mesma letra na coluna não diferem estatisticamente entre si pelo Teste de Tukey $(p>0,05)$.

\section{Conclusão}

O sistema de pulverização pneumática eletrostática mostrou eficiência na aplicação nos diferentes tratamentos fúngicos alternativos devido ao menor volume de calda e indiferença na deposição do produto para 'Niágara Branca' na região de Laranjeiras do Sul-PR. Os diferentes tratamentos fungicidas aplicados em 'Niágara Branca' e 'Niágara Rosada' influenciam no volume de calda aplicado.

\section{Referências}

ANDREAZZA, R. et al. Biorremediação de áreas contaminadas com cobre. Revista de Ciências Agrárias, v. 36, p. 127-136, 2013.

CHAIM, A.; WADT, L. G. Pulverização eletrostática: a revolução na aplicação de agrotóxicos. Notícias: produção vegetal, 01 abril 2015. Disponível em: <https://www.embrapa.br/busca-de-noticias//noticia/2615385/artigo-pulverizacao-letrostatica-a-revolucao-na-aplicacao-de-agrotoxicos>. Acesso em: 29 de março 2016.

CUNHA, J. P. A.; CARVALHO, W. P. Distribuição volumétrica de aplicações aéreas de agrotóxicos utilizando adjuvantes. Engenharia na Agricultura, v.13, n.2, 130-135, 2005.

FARIA, D. et al. Cenários e perspectivas das principais culturas do Rio Grande do Sul em processos de biorrefinaria. Revista Eletrônica Científica Uergs, v.2, n.3, p.291-306, 2016.

MAGNO JÚNIOR, R. G. et al. Desenvolvimento de um dispositivo eletrônico para atração de gotas da aplicação eletrostática em plantas cítricas. Bio Science Journal, v. 27, n. 5, p. 798-804, 2011.

NAVES, R. L.; et al. Sistema de Produção de Uva de Mesa no Norte do Paraná. Embrapa Uva e Vinho. Sistema de Produção, 2005.

PERUCH, L. A. et al. Biomassa cítrica, extrato de algas, calda bordalesa e fosfitos no controle do míldio da videira, cv. Niágara Branca. Revista de Ciências Agroveterinárias, v.6, n.2, p. 143-148, 2007.

RODRIGUES, A. A. et al. Efeito dos extratos vegetais de cinamomo e mamona no controle in vitro de asperisporiumcaricae. Anais... XIV Encontro latino americano de iniciação científica e x encontro latino americano de pós-graduação, 2010.

SASAKI, R. S. et al. Adjuvantes nas propriedades físicas da calda, espectro e eficiência de eletrificação das gotas utilizando a pulverização eletrostática. Ciência Rural, v. 45, n. 2, p.274-279, 2015.

SASAKI, R. S. et al. Deposição e uniformidade de distribuição da calda de aplicação em plantas de café utilizando a pulverização eletrostática. Ciência Rural, v.43, n.9, p. 1605-1609, 2013. 
SERRA, M.; et al. Pontas de pulverização e eletrificação das gotas na deposição da calda em plantas de crisântemo. Pesquisa agropecuária brasileira, p.479-485, 2008.

SILVA, M. M. Avaliação do controle alternativo da antracnose na videira com o uso de extratos vegetais. Dissertação (Mestrado) Universidade Federal de Santa Catarina, 2014.

SILVA, C. M. Controle alternativo do míldio e da antracnose da videira com extrato de cinamomo (Meliaazedarach L.). Dissertação (Mestrado) Universidade estadual do Centro-Oeste, 2011.

SOUZA, L. A.; et al. Deposição do herbicida 2,4-D Amina com diferentes volumes e pontas de pulverização em plantas infestantes. Revista Ciência Agronômica, v. 43, n. 1, p. 78-85, 2012.

VIEIRA, A. C.; WATANABE, M.; BRUCH, K. L. Perspectivas de desenvolvimento da vitivinicultura em face do reconhecimento da indicação de procedência vales da uva 'goethe'. Revista GEINTEC, v. 2, p.327-343, 2012. 